\title{
Organic Anion Transporting Polypeptides 1B1 and 1B3 Play an Important Role in Uremic Toxin Handling and Drug-Uremic Toxin Interactions in the Liver
}

\author{
Toshihiro Sato $^{\mathrm{a}, \mathrm{b}}$, Hiroaki Yamaguchia ${ }^{\mathrm{a}}$, Takuma Kogawa ${ }^{\mathrm{b}}$, Takaaki Abe ${ }^{\mathrm{c}, \mathrm{d}, \mathrm{e}}$, Nariyasu Mano ${ }^{\mathrm{a}}$ \\ a Department of Pharmaceutical Sciences, Tohoku University Hospital, 1-1 Seiryo-machi, Aoba-ku, Sendai 980-8574, \\ Japan. b Laboratory of Clinical Pharmaceutics \& Therapeutics, Division of Pharmasciences, Faculty of \\ Pharmaceutical Sciences, Hokkaido University, Kita-12-jo, Nishi-6-chome, Kita-ku, Sapporo 060-0812, Japan. ${ }^{\mathrm{c}}$ \\ Division of Nephrology, Endocrinology, and Vascular Medicine, Tohoku University, Graduate School of Medicine, \\ 1-1 Seiryo-machi, Aoba-ku, Sendai 980-8574, Japan. ${ }^{\mathrm{d}}$ Division of Medical Science, Tohoku University, Graduate

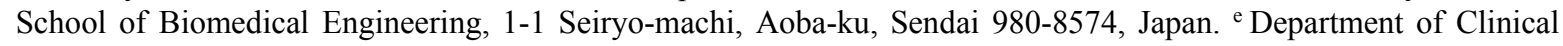 \\ Biology and Hormonal Regulation, Tohoku University, Graduate School of Medicine, 1-1 Seiryo-machi, Aoba-ku, \\ Sendai 980-8574, Japan.
}

Received, July 1, 2014; Revised, September 22, 2014; Accepted, October 24, 2014; Published, October 24, 2014

\begin{abstract}
PURPOSE. Organic anion-transporting polypeptide (OATP) 1B1 and OATP1B3 contribute to hepatic uptake of numerous drugs. Thus, reduced OATP1B1 and OATP1B3 activity in chronic kidney disease (CKD) may have a major impact on the hepatic clearance of drugs. The effect of drug-uremic toxin interactions on OATP1B1 and OATP1B3 has not been well studied. In the present study, we examine the inhibitory effects of uremic toxins on OATP1B1 and OATP1B3 transport activity to evaluate the interactions between drugs and uremic toxins in patients with chronic kidney disease. METHODS. $\left[{ }^{3} \mathrm{H}\right]$ Estron-3-sulfate, $\left[{ }^{3} \mathrm{H}\right]$ taurocholate uptake and $\left[{ }^{3} \mathrm{H}\right]$ methotrexate by OATP1B1 and OATP1B3 expressing HEK293 cells were performed to evaluate the inhibitory effect of uremic toxins. To clarify whether the uremic toxins that interact with OATP1B1 and/or OATP1B3 were substrates for these transporters, we performed uptake studies. RESULTS. Four uremic toxins, kynurenic acid, indole-3-acetic acid, indoxyl sulfate, and $p$-cresol, inhibited OATP1B1- and OATP1B3-mediated transport in a concentration-dependent manner, with $\mathrm{IC}_{50}$ values of $180,770,2700$, and $4600 \mu \mathrm{M}$, respectively, for OATP1B1 and 180,1100, 1300, and $1700 \mu \mathrm{M}$, respectively, for OATP1B3. [ $\left.{ }^{3} \mathrm{H}\right]$ Methotrexate uptake by OATPs was also inhibited by the four uremic toxins in a dose-dependent manner. Uptake studies revealed that kynurenic acid is a substrate for both the OATP1B1 and OATP1B3. Moreover, OATP1B3 was involved in the transport of indoxyl sulfate. Indole-3-acetic acid and $p$-cresol were not significantly transported by OATP1B1 and OATP1B3. CONCLUSIONS. We showed that some uremic toxins inhibit OATP-mediated uptake in a concentration-dependent manner, and clarified OATPs contribution to uremic toxin handling in the liver. Thus, we provided basic information to estimate the inhibitory effects of uremic toxins on OATPs in CKD patients. These data suggest that the dose of drugs excreted via renal and non-renal pathways should be carefully adjusted in CKD patients.
\end{abstract}

This article is open to POST-PUBLICATION REVIEW. Registered readers (see "For Readers") may comment by clicking on ABSTRACT on the issue's contents page.

\section{INTRODUCTION}

Organic anion-transporting polypeptides (OATPs) are a family of sodium-independent organic anion transporters found in a variety of tissues, including the liver, kidney, intestine, and brain. OATPs contribute to the transport of bile acids, thyroid hormones, steroid conjugates, anionic oligopeptides, eicosanoids, and various drugs and xenobiotic compounds across membranes (1-3). OATP1B1 and OATP1B3 are members of the liver-specific subfamily of OATPs, which are localized to the sinusoidal membrane of hepatocytes, and transport a wide variety of clinically used drugs (4-7).

Chronic kidney disease (CKD) causes a negative cycle in which an accumulation of drugs and uremic toxins in blood leads to further impairment of the renal function. The Japanese Society for Dialysis Therapy recently reported that the number of CKD patients requiring artificial dialysis increases by five to ten thousand

Corresponding Author. Hiroaki Yamaguchi, Ph.D. E-mail address: yamaguchi@hosp.tohoku.ac.jp Toshihiro Sato and Hiroaki Yamaguchi: These authors contributed equally to this work. 
a year (8). In CKD patients, uremic toxins and drugs that are typically excreted in the urine accumulate in the body owing to decreased glomerular filtration rates and impairment of renal transporters, such as organic anion transporter (OAT) 1, OAT3, and OATP4C1 (9-13). Drugs excreted in the bile are also affected by the uremic condition of CKD patients (14-16). For example, plasma concentrations of rosuvastatin, which is primarily eliminated through the liver and is a substrate of OATP1B1, are increased 3 -fold in patients with end-stage renal disease (creatinine clearance, CLcr, $<30 \mathrm{~mL} / \mathrm{min}$ ) than in those with healthy subjects (CLcr $>80 \mathrm{~mL} / \mathrm{min}$ ) (17). Plasma concentrations of tadalafil, which is primarily metabolized by CYP3A4, are also reported to be elevated in patients with end-stage renal disease (18).

OATPs regulate access to hepatocellular enzymes and transport into the bile canaliculi, and could be the rate-limiting step in the overall process of hepatic drug clearance $(17,19)$. Although OATPs play an important role in drug handling in CKD patients, few studies have addressed the effect of drug-uremic toxin interactions on these transporters $(16,20-23)$.

In the present study, we examined the inhibitory effects of uremic toxins on OATP1B1and OATP1B3-mediated transport to estimate drug-uremic toxin interactions in CKD patients. Moreover, we tried to clarify which uremic toxins are transported by OATPs.

\section{MATERIALS AND METHODS}

\section{Materials}

Indoxyl sulfate, hippuric acid, creatinine, and $p$-cresol were purchased from Nacalai Tesque, Inc. (Kyoto, Japan). Indole-3-acetic acid was purchased from Kanto Chemical Co., Inc. (Tokyo, Japan). 3-Carboxy-4-methyl-5-propyl-2-furan -propanoic acid (CMPF) was purchased from Cayman Chemical Co. (Ann Arbor, MI). trans-Aconitate, kynurenic acid, L-kynurenine, quinolinic acid (2,3-pyridinedicarboxylic acid), uric acid, and methylguanidine hydrochloride were purchased from Sigma-Aldrich (St. Louis, MO). H-Arg (di-Me) -OH (asymmetrical, ADMA), H-Arg (di-Me) -OH (symmetrical, SDMA), and rifampicin were purchased from Enzo Life Sciences, Inc. (Ann Arbor, MI). Sodium creatine phosphate was purchased from Tokyo Chemical Industry Co., Ltd. (Tokyo, Japan). $\quad\left[{ }^{3} \mathrm{H}\right]$ Estrone-3-sulfate $\quad\left(\mathrm{E}_{3} \mathrm{~S}\right) \quad$ (specific activity: 20-46.5 Ci/mmol) was purchased from
PerkinElmer Life and Analytical Sciences (Waltham, MA). $\left.{ }^{3} \mathrm{H}\right]$ Taurocholate (TCA) (specific activity: $5.0-10 \quad \mathrm{Ci} / \mathrm{mmol}$ ) and $\left[{ }^{3} \mathrm{H}\right]$ indole-3-acetic acid (specific activity: 20 $\mathrm{Ci} / \mathrm{mmol}$ ) were purchased from Muromachi Yakuhin Co., Ltd. (Tokyo, Japan). $\left[{ }^{3} \mathrm{H}\right]$ Methotrexate (MTX) (specific activity: $32.3 \mathrm{Ci} / \mathrm{mmol}$ ) was purchased from Daiichi Clarity Co., Ltd. (Chiba, Japan). All other chemicals were commercially available and of the highest purity possible.

\section{Cell Culture}

Human embryonic kidney (HEK293) cells transduced with OATP1B1, OATP1B3, or an empty vector were previously established $(3,24)$. OATP1B1/HEK293, OATP1B3/HEK293 cells, and mock cells were cultured in Dulbecco's modified Eagle's medium supplemented with $10 \%$ fetal bovine serum and G418 $(0.5 \mathrm{mg} / \mathrm{mL})$ under an atmosphere of $5 \% \mathrm{CO}_{2}$ and $95 \%$ air at $37^{\circ} \mathrm{C}$.

\section{Transport Studies}

The cellular uptake in monolayer cultures grown on 24-well plates was measured. After washing once, the cells were preincubated in Krebs-Henseleit (KH) buffer $(118 \mathrm{mM} \mathrm{NaCl}$, $23.8 \mathrm{mM} \mathrm{NaHCO}, 4.83 \mathrm{mM} \mathrm{KCl}, 0.96 \mathrm{mM}$ $\mathrm{KH}_{2} \mathrm{PO}_{4}, \quad 1.20 \quad \mathrm{mM} \quad \mathrm{MgSO}_{4}, \quad 12.5 \mathrm{mM}$ $N$-(2-hydroxyethyl) piperazine $-N^{\prime}-2$ ethanesulfonic acid [HEPES], $5.0 \mathrm{mM}$ D-glucose, and $1.53 \mathrm{mM} \mathrm{CaCl}, \mathrm{pH}$ 7.4). Uptake was initiated by adding either substrates $\left(\left[{ }^{3} \mathrm{H}\right] \mathrm{E}_{3} \mathrm{~S}\right.$, $\left[{ }^{3} \mathrm{H}\right] \mathrm{TCA}$ and $\left.\left[{ }^{3} \mathrm{H}\right] \mathrm{MTX}\right)$ or uremic toxins ( $\left[{ }^{3} \mathrm{H}\right]$ indole-3-acetic acid, kynurenic acid, indoxyl sulfate, and $p$-cresol). At the indicated times, uptake was terminated by replacing the uptake buffer with ice-cold $\mathrm{KH}$ buffer, and then washing two times with ice-cold $\mathrm{KH}$ buffer. Intracellular accumulation of radioactivity was measured using a liquid scintillation counter (Packard, 1600TR). Kynurenic acid, indoxyl sulfate, and $p$-cresol were measured by liquid chromatography/tandem mass spectrometry (LC/MS/MS). The protein content of the solubilized cells was determined by the Bradford method using a Protein Assay kit (Bio-Rad Laboratories Inc., Hercules, CA) with bovine serum albumin as a standard.

\section{Inhibitory Effects of Uremic Toxins}

We calculated the $\mathrm{IC}_{50}$ value of the uremic toxins that inhibited OATP1B1 and OATP1B3 over 50\%. The $\mathrm{IC}_{50}$ values were estimated using a nonlinear 
regression analysis of the competition curves with a one-compartment model using the following equation: $\mathrm{V}=100 \times \mathrm{IC}_{50} /\left(\mathrm{IC}_{50}+[\mathrm{I}]\right)+$ $\mathrm{A}$, where $\mathrm{V}$ is the transport amount (\% of control), [I] is the concentration of uremic toxins, and A is the nonspecific transport (\% of control) using software Origin 8 (Lightstone Corp., Tokyo, Japan).

\section{Assay of Uremic Toxins by LC/MS/MS}

Cells were scraped and homogenized in $250 \mu \mathrm{L}$ of water for kynurenic acid analysis and $100 \mu \mathrm{L}$ of water for indoxyl sulfate and $p$-cresol analyses. Cell lysates were deproteinized by adding equal volumes of acetonitrile. The mixture was vortexed and centrifuged at $12,000 \times g$ for $10 \mathrm{~min}$ at room temperature. The supernatants were used directly for indoxyl sulfate and $p$-cresol measurement. For the measurement of kynurenic acid, the supernatant was evaporated at $40-60{ }^{\circ} \mathrm{C}$, and the residue was reconstituted in $50 \mu \mathrm{L}$ of mobile phase. Chromatographic separation was carried out using a Shimadzu Prominence 20A System (Shimadzu, Kyoto, Japan) with a Shiseido CAPCELL PAK C18 MGIII column $(2.0 \mathrm{~mm} \times 50 \mathrm{~mm}, 3 \mu \mathrm{m})$. For the determination of kynurenic acid, the column was eluted with an isocratic flow of acetonitrile/water/acetic acid $(30: 70: 0.1, \mathrm{v} / \mathrm{v} / \mathrm{v})$ at a flow rate of $0.3 \mathrm{~mL} / \mathrm{min}$. The injection volume was $5 \mu \mathrm{L}$. Indoxyl sulfate was eluted with a binary flow of acetonitrile and water at a flow rate of $0.2 \mathrm{~mL} / \mathrm{min}$. Acetonitrile increased from $5 \%$ to $60 \%$ in a linear gradient over $2 \mathrm{~min}$ and held until $5 \mathrm{~min}$. Acetonitrile decreased to $5 \%$ from $5 \mathrm{~min}$ to $5.1 \mathrm{~min}$ and held until $8.1 \mathrm{~min}$. The injection volume was $1 \mu \mathrm{L}$. $p$-Cresol was also eluted with a binary flow of methanol and water at a flow rate of $0.2 \mathrm{~mL} / \mathrm{min}$. Methanol was increased from $30 \%$ to $95 \%$ in a linear gradient over $3 \mathrm{~min}$ and held until $5 \mathrm{~min}$. Then methanol was decreased to $30 \%$ from $5 \mathrm{~min}$ to $5.1 \mathrm{~min}$ and held until $9.1 \mathrm{~min}$. The injection volume was $1 \mu \mathrm{L}$. The column temperature was kept at $40^{\circ} \mathrm{C}$. Negative ion electrospray tandem mass spectrometric analysis was carried out using an API 3200 LC/MS/MS System at unit resolution with selected reaction monitoring $(\mathrm{m} / \mathrm{z}$ $188>144$ for kynurenic acid, $m / z 212>79.8$ for indoxyl sulfate, and $m / z 107>76.9$ for $p$-cresol). Data were acquired and analyzed using Analyst software (version 1.5) (Applied Biosystems) (Foster City, CA, USA)).

\section{Statistical Analysis}

Data are expressed as mean \pm S.E.M. When appropriate, the differences between groups were tested for significance using the unpaired Student's t-test. Statistical significance was indicated by $p$ values less than 0.05 .

\section{RESULTS}

\section{Inhibitory Effects of Uremic Toxins on OATP1B1- and OATP1B3-Mediated Transport}

We first examined the inhibitory effects of uremic toxins on OATP1B1- and OATP1B3-mediated transport. Uptake experiments using $\left[{ }^{3} \mathrm{H}\right] \mathrm{E}_{3} \mathrm{~S}$ for OATP1B1 and $\left[{ }^{3} \mathrm{H}\right]$ TCA for OATP1B3, which are known substrates for each transporter, were performed. Eighteen uremic toxins with a variety of functional groups were selected (Table 1). The results of the screening showed that $1000 \mu \mathrm{M}$ kynurenic acid, $10000 \mu \mathrm{M}$ indole-3-acetic acid, $10000 \mu \mathrm{M}$ indoxyl sulfate, and $10000 \mu \mathrm{M}$ $p$-cresol inhibited both OATP1B1- and OATP1B3-mediated transport more than 50\%. CMPF $(1000 \mu \mathrm{M})$ and urea $(10000 \mu \mathrm{M})$ also inhibited both OATP1B1- and OATP1B3-mediated transport, but the inhibition by these uremic toxins was moderate (greater than $20 \%$, less than $50 \%)$. L-Kynurenine (1000 $\mu \mathrm{M})$ selectively decreased OATP1B1-mediated transport by $22 \%$. SDMA selectively decreased OATP1B3-mediated transport by $47 \%$, but the inhibition of SDMA was not concentration-dependent (SDMA: 1-1000 $\mu \mathrm{M}$, data not shown). No significant inhibition to OATP1B1-mediated transport was observed with $10000 \mu \mathrm{M}$ creatinine, $10000 \mu \mathrm{M}$ guanidine, 1000 $\mu \mathrm{M}$ methylguanidine, $10000 \mu \mathrm{M}$ hippuric acid, and $100000 \mu \mathrm{M}$ mannitol. However, all of these uremic toxins moderately inhibited (greater than $20 \%$, less than 50\%) OATP1B3-mediated transport. The inhibitory effects of most uremic toxins on OATPs were higher than those observed with clinical concentrations.

Next, we evaluated the $\mathrm{IC}_{50}$ of the four uremic toxins (kynurenic acid, indole-3-acetic acid, indoxyl sulfate, and $p$-cresol) that inhibited OATPs by more than $50 \%$. The four uremic toxins inhibited OATP1B1- and OATP1B3 -mediated transport in a concentration-dependent manner (Fig. 1 and 2).

The $\mathrm{IC}_{50}$ values of kynurenic acid, indole-3-acetic acid, indoxyl sulfate, and $p$-cresol for OATP1B1 were $180 \pm 110 \mu \mathrm{M}, 770 \pm 130 \mu \mathrm{M}$, $2700 \pm 290 \mu \mathrm{M}$, and $4600 \pm 790 \mu \mathrm{M}$, and the corresponding values for OATP1B3 were $180 \pm$ $20 \mu \mathrm{M}, \quad 1100 \pm 330 \mu \mathrm{M}, 1300 \pm 420 \mu \mathrm{M}$, and 
Table 1. Chemical Structures, Clinical Concentrations and Inhibitory Effects of Uremic Toxins on OATPs

\begin{tabular}{|c|c|c|c|c|c|}
\hline \multirow{2}{*}{ Uremic Toxin } & \multirow{2}{*}{$\begin{array}{l}\text { Chemical } \\
\text { Structure }\end{array}$} & \multirow{2}{*}{$\begin{array}{l}\text { Concentration } \\
\qquad(\mu \mathrm{M})\end{array}$} & \multicolumn{2}{|c|}{ Transport ( \% ) } & \multirow{2}{*}{$\begin{array}{l}\text { Clinical Conc. } \\
\qquad(\mu \mathrm{M})\end{array}$} \\
\hline & & & OATP1B1 & OATP1B3 & \\
\hline \multicolumn{6}{|l|}{ Guanidines } \\
\hline ADMA & & 100 & $86 \pm 14$ & $127 \pm 14$ & $0.69-36^{(28) *}$ \\
\hline SDMA & & 1000 & $92 \pm 18$ & $53 \pm 3.7$ & $0.27-6.1^{(28) *}$ \\
\hline Creatine & & 10000 & $98 \pm 8.6$ & $82 \pm 9.9$ & $48-1800^{(28) *}$ \\
\hline Creatinine & & 10000 & $102 \pm 12$ & $67 \pm 6.4$ & $110-2100^{(28) *}$ \\
\hline Guanidine & & 10000 & $102 \pm 5.9$ & $77 \pm 11$ & $0.20-14^{(28) *}$ \\
\hline Guanidinoacetic acid & & 10000 & $104 \pm 5.5$ & $98 \pm 18$ & $1.2-5.9^{(28) *}$ \\
\hline Methylguanidine & & 1000 & $105 \pm 4.6$ & $69 \pm 12$ & $0.10-25^{(28) *}$ \\
\hline \multicolumn{6}{|l|}{ Hippurates } \\
\hline Hippuric acid & & 10000 & $93 \pm 7.6$ & $57 \pm 4.6$ & $28-2600^{(28)}$ \\
\hline \multicolumn{6}{|l|}{ Indoles } \\
\hline \multirow{2}{*}{ Indole-3-acetic acid } & & 1000 & $54 \pm 2.1$ & $65 \pm 11$ & \multirow{2}{*}{$0.10-52^{(28)}$} \\
\hline & & 10000 & $24 \pm 2.9$ & $12 \pm 5.3$ & \\
\hline \multirow{2}{*}{ Indoxyl sulfate } & & 1000 & $82 \pm 7.8$ & $59 \pm 9.9$ & \multirow{2}{*}{$2.4-940^{(28)}$} \\
\hline & & 10000 & $42 \pm 3.4$ & $22 \pm 9.7$ & \\
\hline \multirow{2}{*}{ Kynurenic acid } & & 100 & $92 \pm 0.7$ & $71 \pm 14$ & \multirow{2}{*}{$5.3-50^{(28)}$} \\
\hline & & 1000 & $43 \pm 2.3$ & $23 \pm 5.2$ & \\
\hline L-Kynurenine & & 1000 & $78 \pm 2.5$ & $104 \pm 7.7$ & $0.7-4.6^{(28,35)}$ \\
\hline Quinolinic acid & & 1000 & $116 \pm 3.5$ & $93 \pm 25$ & $0.16-20^{(28,35)}$ \\
\hline \multicolumn{6}{|l|}{ Phenols } \\
\hline \multirow{2}{*}{$p$-Cresol } & & 1000 & $96 \pm 6.5$ & $84 \pm 6.4$ & \multirow{2}{*}{$5.6-380^{(28)}$} \\
\hline & & 10000 & $16 \pm 1.3$ & $1.8 \pm 8.4$ & \\
\hline \multicolumn{6}{|l|}{ Polyols } \\
\hline Mannitol & & 10000 & $101 \pm 7.7$ & $72 \pm 18$ & $7.1-420^{(28) *}$ \\
\hline \multicolumn{6}{|l|}{ Others } \\
\hline CMPF & & 1000 & $79 \pm 5.6$ & $75 \pm 12$ & $18-390^{(28)}$ \\
\hline trans-Aconitate & & 1000 & $106 \pm 7.7$ & $86 \pm 8.6$ & $0.5-6.5^{(36)}$ \\
\hline Urea & & 100000 & $72 \pm 5.3$ & $62 \pm 9.3$ & $6700-77000^{(28) *}$ \\
\hline
\end{tabular}

CMPF: 3-carboxy-4-methyl-5-propyl-2-furanpropanoic acid, ADMA： H-Arg(di-Me)-OH (asymmetrical); SDMA: $\mathrm{H}-\mathrm{Arg}(\mathrm{di}-\mathrm{Me})-\mathrm{OH}$ (symmetrical); Asterisk indicates free concentration of uremic toxin (protein unbound) transport (\%) are shown as mean \pm S.E.M. $(n=3-6)$. 
$1700 \pm 85 \mu \mathrm{M}$. Indole-3-acetic acid strongly inhibited OATP1B1-mediated transport $\left(\mathrm{IC}_{50} 770\right.$ $\mu \mathrm{M})$ more than that of OATP1B3 $\left(\mathrm{IC}_{50} 1100 \mu \mathrm{M}\right)$. Indoxyl sulfate and $p$-cresol had a higher affinity for OATP1B3 than for OATP1B1. Compared to the other uremic toxins, kynurenic acid inhibited the transport activity of OATP1B1 and OATP1B3 with relatively high affinity.

\section{Drug-Uremic Toxin Interactions on OATP1B1 and OATP1B3}

We next examined the inhibitory effects of kynurenic acid, indole-3-acetic acid, indoxyl sulfate, and $p$-cresol on OATP1B1- and OATP1B3-mediated drug transport. We performed uptake experiments using $\left[{ }^{3} \mathrm{H}\right] \mathrm{MTX}$ as a model substrate of OATP1B1 and OATP1B3. $\left[{ }^{3} \mathrm{H}\right] \mathrm{MTX}$ uptake by OATP1B1- and OATP1B3-expressing HEK293 cells was inhibited by the four uremic toxins in a concentration-dependent manner (Fig. 3). Rifampicin, a known inhibitor of OATPs, was used as a positive control. OATP1B1- and OATP1B3-mediated $\left[{ }^{3} \mathrm{H}\right] \mathrm{MTX}$ uptake were inhibited $57 \pm 30 \%$ and $4.7 \pm 3.9 \%$ versus control, respectively, by $10 \mu \mathrm{M}$ rifampicin. The uremic toxins inhibited OATP1B1- and OATP1B3-mediated $\left[{ }^{3} \mathrm{H}\right]$ MTX uptake in a similar manner.

\section{Uptake of Uremic Toxins by OATP1B1- and OATP1B3-Expressing HEK293 Cells}

To clarify whether the uremic toxins that interact with OATP1B1 and/or OATP1B3 were substrates for these transporters, we performed uptake studies. Kynurenic acid uptake was significantly higher in OATP1B1- and OATP1B3-expressing HEK293 cells than in mock cells $(1.1,1.6$, and $2.0 \mathrm{pmol} / \mathrm{mg}$ protein $/ 2 \mathrm{~min}$ for mock, OATP1B1/HEK293, and OATP1B3/HEK293 cells, respectively) (Fig. 4A). Moreover, indoxyl sulfate uptake was significantly higher in OATP1B3-expressing HEK293 cells than in controls (11 and $14 \mathrm{pmol} / \mathrm{mg}$ protein $/ 2 \mathrm{~min}$ for mock and OATP1B3/HEK293 cells, respectively), but not in OATP1B1-expressing HEK293 cells (Fig. 4C). No significant indole-3-acetic acid and $p$-cresol transport was observed by OATP1B1- or OATP1B3-expressing HEK293 cells (Fig. 4B and D).

B

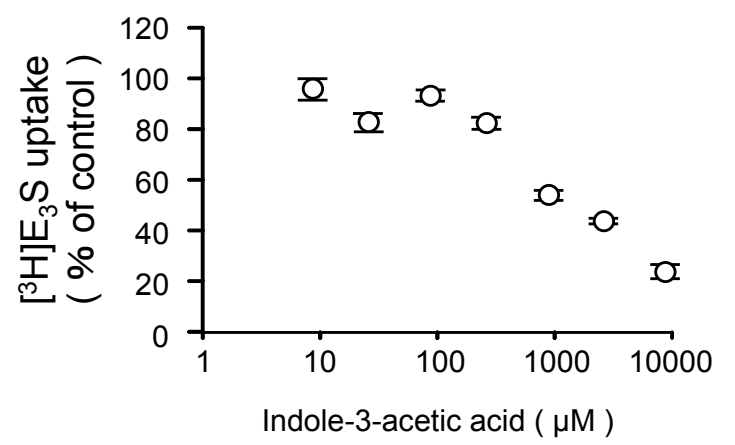

D

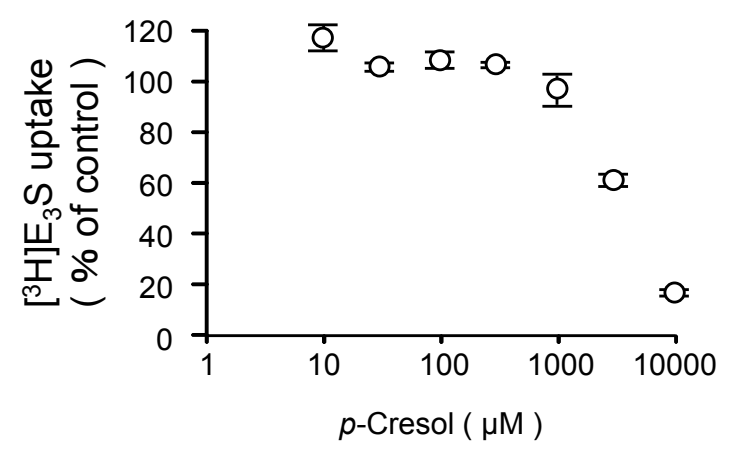

Figure 1. Inhibitory effects of uremic toxins (kynurenic acid (A), indole-3-acetic acid (B), indoxyl sulfate (C), and $p$-cresol (D)) on OATP1B1-mediated transport. Cells were incubated for $15 \mathrm{sec}$ at $37{ }^{\circ} \mathrm{C}$ with $9.2-11 \mathrm{nM}\left[{ }^{3} \mathrm{H}\right] \mathrm{E}_{3} \mathrm{~S}$ in the presence or absence of uremic toxins. OATP1B1-mediated transport was calculated after subtracting nonspecific uptake by mock cells. Each point and bar represents the mean \pm S.E.M. $(\mathrm{n}=3)$. 


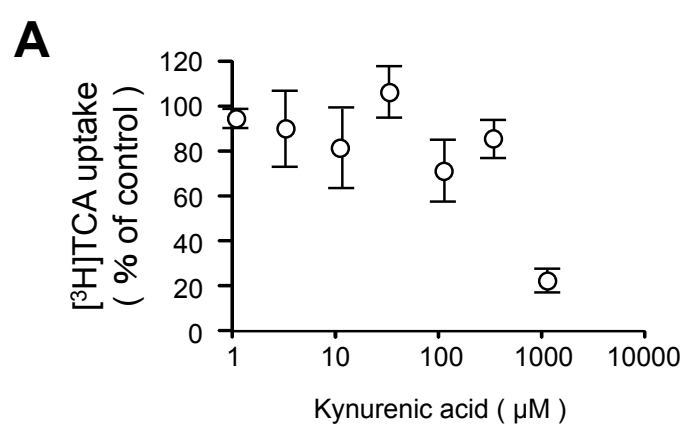

B

C

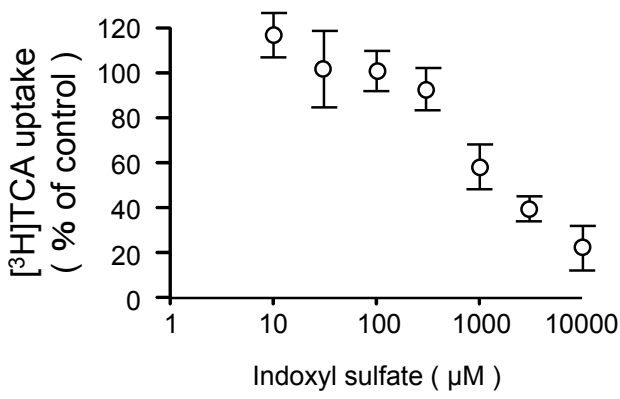

\section{D}
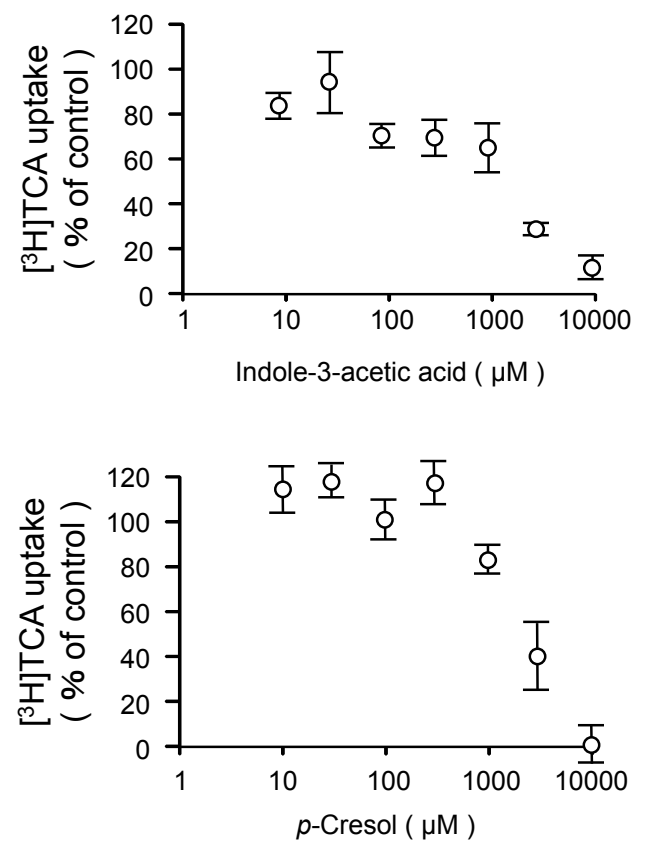

Figure 2. Inhibitory effects of uremic toxins (kynurenic acid (A), indole-3-acetic acid (B), indoxyl sulfate (C), and $p$-cresol (D)) on OATP1B3-mediated transport. Cells were incubated for 2 min at $37^{\circ} \mathrm{C}$ with $50-100 \mathrm{nM}\left[{ }^{3} \mathrm{H}\right] \mathrm{TCA}$ in the presence or absence of uremic toxins. OATP1B3-mediated transport was calculated after subtracting nonspecific uptake by mock cells. Each point and bar represents the mean \pm S.E.M. ((A), (B) and (D) $(n=3),(C)(n=5-6))$.

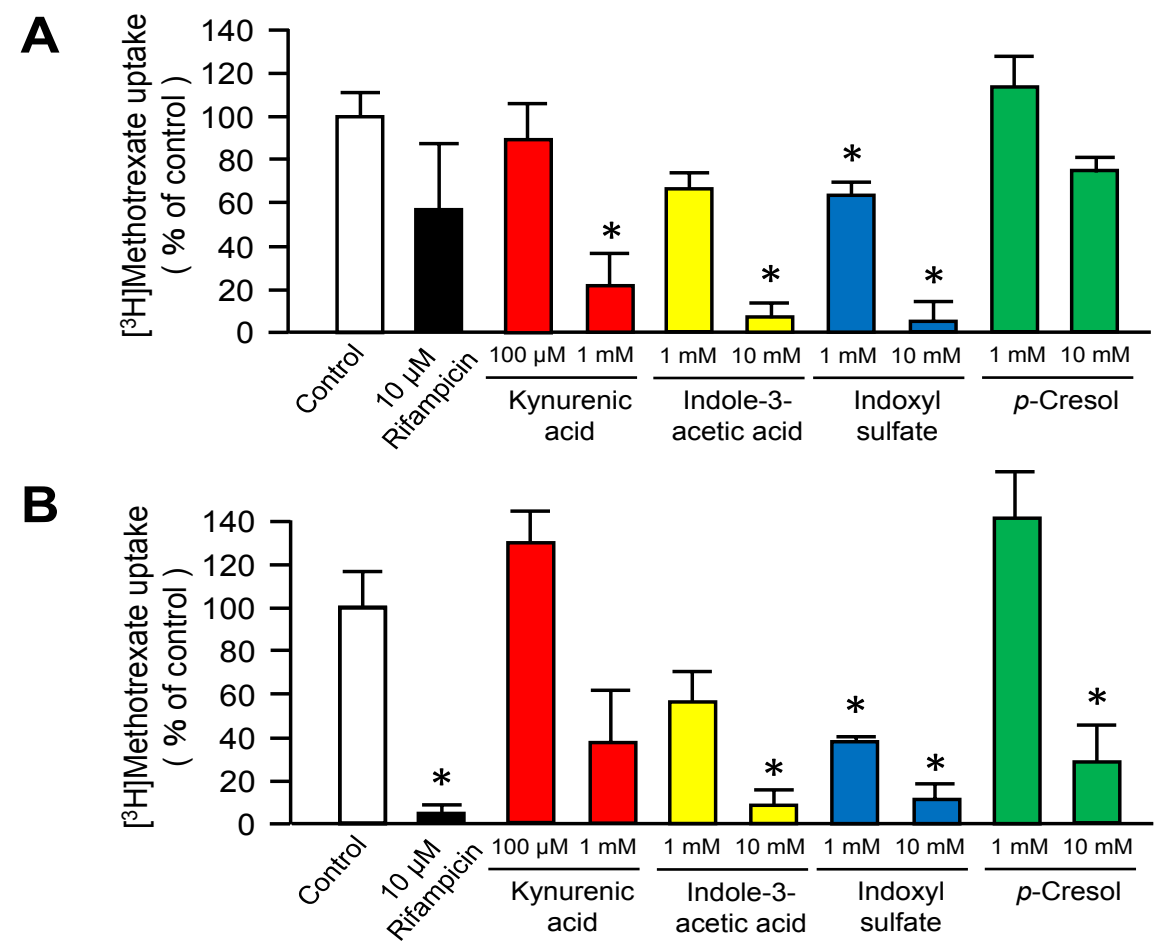

Figure 3. Inhibitory effects of uremic toxins on $\left[{ }^{3} \mathrm{H}\right] \mathrm{MTX}$ uptake by OATP1B1- (A) and OATP1B3-expressing HEK293 cells (B). Cells were incubated for $5 \mathrm{~min}$ at $37{ }^{\circ} \mathrm{C}$ with $16 \mathrm{nM}\left[{ }^{3} \mathrm{H}\right] \mathrm{MTX}$ in the presence or absence of uremic toxins and $10 \mu \mathrm{M}$ rifampicin. Open column represents $\left[{ }^{3} \mathrm{H}\right] \mathrm{MTX}$ uptake in the absence of inhibitors (control). Closed, red, yellow, blue and green columns represent the inhibitory effects of $10 \mu \mathrm{M}$ rifampicin, kynurenic acid, indole-3-acetic acid, indoxyl sulfate and $p$-cresol on OATP1B1- and OATP1B3-mediated $\left[{ }^{3} \mathrm{H}\right] \mathrm{MTX}$ transport. OATP1B1- and OATP1B3-mediated transport was calculated after subtracting nonspecific uptake by mock cells. Each column represents the mean \pm S.E.M. $(\mathrm{n}=3)$. Asterisk indicates a significant difference from control value $(p<$ $0.05)$. 

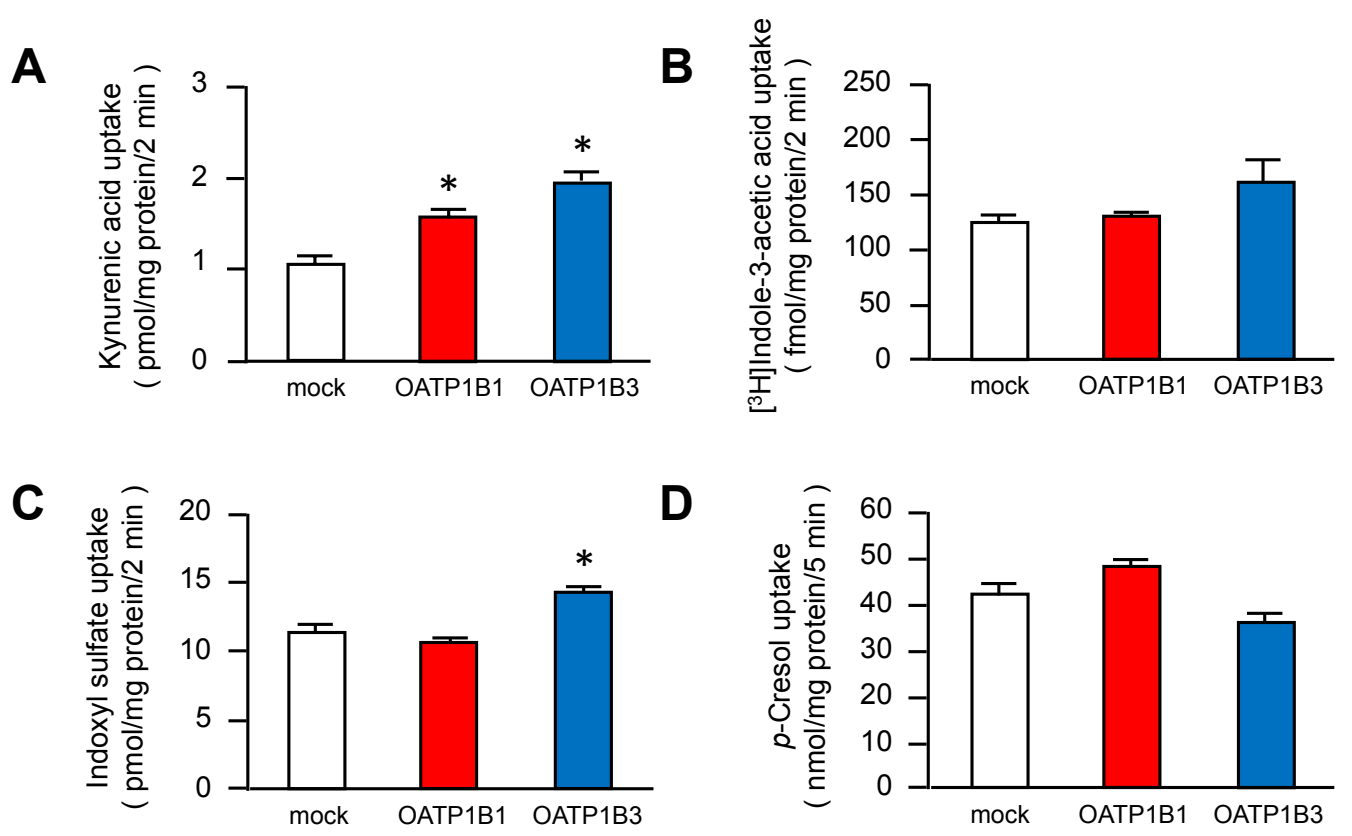

Figure 4. Uremic toxins (kynurenic acid (A), indole-3-acetic acid (B), indoxyl sulfate (C), and p-cresol (D)) uptake by OATP1B1- and OATP1B3-expressing HEK293 cells. OATP1B1- (red columns), OATP1B3-expressing HEK293 cells (blue columns), or mock cells (open columns) were incubated at $37{ }^{\circ} \mathrm{C}$ for 2 min with $10 \mu \mathrm{M}$ kynurenic acid, 25 $\mathrm{nM}\left[{ }^{3} \mathrm{H}\right]$ indole-3-acetic acid, $50 \mu \mathrm{M}$ indoxyl sulfate, $100 \mu \mathrm{M} p$-cresol. Each column represents the mean \pm S.E.M. (n $=3)$. Asterisk indicates a significant difference from value of mock cells $(p<0.05)$.

\section{DISCUSSION}

In the present study, we evaluated the interaction of uremic toxins with the hepatic organic anion transporters OATP1B1 and OATP1B3. This is the first report to quantify the effects of four representative uremic toxins (kynurenic acid, indole-3-acetic acid, indoxyl sulfate, and $p$-cresol) on OATP1B1- and OATP1B3-mediated transport. Our results indicate that some uremic toxins are substrates of OATP1B1 and/or OATP1B3.

From the screening results, we found that OATP1B1-mediated $\left[{ }^{3} \mathrm{H}\right] \mathrm{E}_{3} \mathrm{~S}$ transport and OATP1B3-mediated $\left[{ }^{3} \mathrm{H}\right] \mathrm{TCA}$ transport were inhibited by kynurenic acid, indole-3-acetic acid, indoxyl sulfate, and $p$-cresol in a dose-dependent manner (Fig. 1 and 2). These four uremic toxins affected both OATP1B1 and OATP1B3, with $\mathrm{IC}_{50}$ values of 180 and $180 \mu \mathrm{M}$ for kynurenic acid, 770 and $1100 \mu \mathrm{M}$ for indole-3-acetic acid, 2700 and 1300 for indoxyl sulfate, and 4600 and 1700 $\mu \mathrm{M}$ for $p$-cresol, respectively. We also identified several uremic toxins that moderately inhibited OATP1B1- and OATP1B3-mediated transport (greater than $20 \%$, less than 50\%) (Table 1). The data showed that only L-kynurenine selectively inhibited OATP1B1-mediated transport, whereas five uremic toxins (creatinine, guanidine, methylguanidine, hippuric acid, and mannitol) selectively inhibited OATP1B3-mediated transport. Two uremic toxins (CMPF and urea) moderately inhibited both OATP1B1- and OATP1B3-mediated transport. Moreover, the effects of CMPF and urea on OATPs occurred at clinically relevant concentrations. This data suggests that indoxyl sulfate, $p$-cresol, and many uremic toxins had a stronger inhibitory effect on OATP1B3-mediated transport. These results suggest that typical and selective substrates of OATP1B3, such as telmisartan, may be affected by uremic toxins to a greater extent than substrates of both OATP1B1 and OATP1B3 in CKD patients (25).

According to previous reports, CMPF was the most potent inhibitor of OATP for the uptake of erythromycin, eprosartan, and digoxin, with a $K_{\text {i value of }} 20$ to $50 \mu \mathrm{M}(16,20,21)$. In another report, it was shown that the $\mathrm{IC}_{50}$ values of CMPF, indoxyl sulfate, hippuric acid, and indole-3-acetic acid were $>300 \mu \mathrm{M}, 4750 \mu \mathrm{M},>3000 \mu \mathrm{M}$, and $>3000 \mu \mathrm{M}$, respectively (26). Moreover, OATP1B1-mediated SN-38 uptake was strongly inhibited by CMPF and indoxyl sulfate, with $\mathrm{IC}_{50}$ values of $158 \mu \mathrm{M}$ and $2290 \mu \mathrm{M}$, respectively (26). The $\mathrm{IC}_{50}$ values of CMPF, indoxyl sulfate, 
hippuric acid, and indole-3-acetic acid were different from those obtained in our studies. The reason why the $\mathrm{IC}_{50}$ values of uremic toxins were different is unclear.

Next, we performed an uptake study using $\left[{ }^{3} \mathrm{H}\right] \mathrm{MTX}$ as a model drug to examine the inhibitory effects of uremic toxins on OATP1B1and OATP1B3-mediated drug transport. $\left[{ }^{3} \mathrm{H}\right] \mathrm{MTX}$ uptake by OATP1B1- and OATP1B3-expressing HEK293 cells was significantly inhibited by the four uremic toxins examined (kynurenic acid, indole-3-acetic acid, indoxyl sulfate, and $p$-cresol). The uremic toxins inhibited $\left[{ }^{3} \mathrm{H}\right] \mathrm{MTX}$ uptake by OATP1B1- and OATP1B3-expressing HEK293 cells in a concentration-dependent manner (Fig. 3). Rifampicin decreased both OATP1B1- and OATP1B3-mediated $\left[{ }^{3} \mathrm{H}\right] \mathrm{MTX}$ uptake $57 \%$ and $4.7 \%$, respectively (Fig. 3). In the previous report, the $\mathrm{IC}_{50}$ values of rifampicin were evaluated as $8.8 \mu \mathrm{M}$ for OATP1B1 and $3.9 \mu \mathrm{M}$ for OATP1B3, respectively [3]. Vavricka et al. have reported that the apparent $K_{\mathrm{m}}$ value of rifampicin transport was $13 \mu \mathrm{M}$ for OATP1B1 and $2.3 \mu \mathrm{M}$ for OATP1B3 (27). This supports our screening results, and the $\mathrm{IC}_{50}$ values of uremic toxins. Therefore, the $\mathrm{IC}_{50}$ values in our study can be used to accurately estimate the inhibitory effects of these transporters.

When we calculate the effect of uremic toxins, the binding affinities of uremic toxins, such as kynurenic acid, indole-3-acetic acid, indoxyl sulfate, hippuric acid, and CMPF for serum protein must be considered. Almost $90 \%$ of uremic toxins exist in the protein-bound form in plasma sera (28). Thus, the effects of uremic toxins on OATPs are thought to be smaller under normal conditions. However, in chronic disease states, such as CKD, uremic toxins may have a greater effect. For instance, CKD patients frequently have hypoalbuminemia, resulting in an increase in protein-unbound uremic toxins (29). Moreover, it was reported that compared to control subjects, dialyzed patients have significantly lower levels of albumin (30). Therefore, we could estimate the inhibitory effects of uremic toxins on OATPs by using the $\mathrm{IC}_{50}$ values in $\mathrm{CKD}$ patients. When we calculated the inhibitory effects using the equation $(\mathrm{V}=100$ $\left.\times \mathrm{IC}_{50} /\left(\mathrm{IC}_{50}+[\mathrm{I}]\right)+\mathrm{A}\right)$, kynurenic acid, indole-3-acetic acid, indoxyl sulfate, and $p$-cresol decreased OATP1B1 transport to 78, 94, 74, and $92 \%$ at maximum concentration of the uremic toxins in CKD patients shown in Table 1, and the corresponding values for OATP1B3 transport were $78,96,58$, and $82 \%$. Compared to other uremic toxins, indoxyl sulfate may strongly affect OATP1B3 transport at clinically relevant concentration. Although each uremic toxin may show weak inhibitory effect on OATPs singly, inhibitory effects of many uremic toxins on OATPs should be strengthened additively and synergistically in CKD patients. We therefore need to carefully adjust the doses of drugs excreted via both renal and non-renal pathways in CKD patients.

We also assessed the uptake of kynurenic acid, indole-3-acetic acid, indoxyl sulfate, and $p$-cresol by OATPs to better understand the affinity of uremic toxins to OATPs. Our results indicate that kynurenic acid is the substrate of both OATP1B1 and OATP1B3, and that indoxyl sulfate is the substrate of OATP1B3. Indole-3-acetic acid and $p$-cresol were not significantly transported by OATP1B1 and OATP1B3. In previous studies, some uremic toxins have been reported to inhibit CYPs (15, 31). These uremic toxins also alter the expression of hepatic transporters $(32,33)$. For instance, the plasma concentration of tadalafil, which is primarily metabolized by CYP3A4, is elevated in patients with end-stage renal disease (18). Further, the plasma concentration of tadalafil is affected not only by CYP3A4 but also by OATP1B1 expression (34). Although it is important to know hepatic uptake process of uremic toxin, little information is available in this regard. Previous reports and our results suggest that hepatic uptake of the uremic toxins via OATP1B1 and OATP1B3 plays an important role in access to the intracellular environment, and that the accumulation of uremic toxins via OATP1B1 and OATP1B3 can alter the expression levels of hepatocellular enzymes and transporters $(14,37$, 38). Thus, additional studies about the detailed mechanisms of hepatic uremic toxins uptake are needed to inform the hepatotoxicity induced by uremic toxins and drug-uremic toxin interactions in patients with CKD.

In conclusion, we have demonstrated that some uremic toxins inhibit OATP-mediated uptake in a concentration-dependent manner, and have clarified OATPs contribution to uremic toxin handling in the liver. Thus, we provided basic information to estimate the inhibitory effects of uremic toxins on OATPs in CKD patients. Accumulated uremic toxins affect the uptake of various substrates by OATPs in the liver, and the uptake of endogenous compounds in hepatocytes may also be affected, potentially 
leading to liver injury. We therefore emphasize the necessity of careful adjustment of doses for drugs excreted by renal and non-renal pathways in CKD patients.

\section{DECLARATION}

\section{Conflict of interest}

The Authors declare that they have no conflicts of interest to disclose.

\section{ACKNOWLEDGEMENTS}

This study was supported in part by JSPS KAKENHI Grant Number 23790168 and by the Nakatomi Foundation (HY).

\section{REFERENCES}

1. Hagenbuch B, Meier PJ. The superfamily of organic anion transporting polypeptides. Biochim Biophys Acta 2003; 1609: 1-18.

2. Mikkaichi $\mathrm{T}$ et al. The organic anion transporter (OATP) family. Drug Metab Pharmacokin 2004; 19: 171-179.

3. Yamaguchi $\mathrm{H}$ et al. Screening of antibiotics that interact with organic anion-transporting polypeptides 1B1 and 1B3 using fluorescent probes. Biol Pharm Bull 2011; 34: 389-395.

4. Abe $\mathrm{T}$ et al. Identification of a novel gene family encoding human liver-specific organic anion transporter LST-1. J Biol Chem 1999; 274: 17159-17163.

5. Abe $\mathrm{T}$ et al. LST-2, a human liver-specific organic anion transporter, determines methotrexate sensitivity in gastrointestinal cancers. Gastroenterology 2001; 120: 1689-1699.

6. König $J$ et al. A novel human organic anion transporting polypeptide localized to the basolateral hepatocyte membrane. Am J Physiol Gastrointest Liver Physiol 2004; 278: G156-G164.

7. Cui $Y$ et al. Detection of the human organic anion transporters SLC21A6 (OATP2) and SLC21A8 (OATP8) in liver and hepatocellular carcinoma. Lab Invest 2003; 83: 527-538.

8. Nakai $\mathrm{S}$ et al. Overview of regular dialysis treatment in Japan (as of 31 December 2011). Ther Apher Dial 2013; 17: 567-611.

9. Tsutsumi $\mathrm{Y}$ et al. Renal disposition of a furan dicarboxylic acid and other uremic toxins in the rat. J Pharmacol Exp Ther 2002; 303: 880-7.

10. Enomoto A et al. Role of organic anion transporters in the tubular transport of indoxyl sulfate and the induction of its nephrotoxicity. $\mathrm{J}$
Am Soc Nephrol 2002; 13: 1711-1720.

11. Yamaguchi $\mathrm{H}$ et al. Transport of estrone 3-sulfate mediated by organic anion transporter OATP4C1: estrone 3-sulfate binds to the different recognition site for digoxin in OATP4C1. Drug Metabol Pharmacokinet 2010; 25: 314-317.

12. Miyamoto $\mathrm{Y}$ et al. Organic anion transporters play an important role in the uptake of $p$-cresyl sulfate, a uremic toxin, in the kidney. Nephrol Dial Transplant 2011; 26: 2498-502.

13. Uwai $Y$ et al. Interaction and transport of kynurenic acid via human organic anion transporters hOAT1 and hOAT3. Pharmacol Res 2012; 65: 254-260.

14. Sun $\mathrm{H}$ et al. Effects of renal failure on drug transport and metabolism. Pharmacol Ther 2006; 109: 1-11.

15. Dreisbach AW, Lertora JJ. The effect of chronic renal failure on drug metabolism and transport. Expert Opin Drug Metab Toxicol 2008; 4: 1065-1074.

16. Tsujimoto $\mathrm{M}$ et al. Effects of uremic serum and uremic toxins on hepatic uptake of digoxin. Ther Drug Monit 2008; 30: 576-582.

17. Yeung $\mathrm{CK}$ et al. Effects of chronic kidney disease and uremia on hepatic drug metabolism and transport. Kidney Int 2014; 85: 522-528.

18. Forgue ST et al. Effects of gender, age, diabetes mellitus and renal and hepatic impairment on tadalafil pharmacokinetics. Br J Clin Pharmacol 2007; 63: 24-35.

19. Fenner KS et al. The evolution of the OATP hepatic uptake transport protein family in DMPK sciences: from obscure liver transporters to key determinants of hepatobiliary clearance. Xenobiotica 2012; 42: 28-45.

20. Sun $\mathrm{H}$ et al. Effects of uremic toxins on hepatic uptake and metabolism of erythromycin. Drug Metab Dispos 2004; 32: 1239-46.

21. Sun $\mathrm{H}$ et al. Uremic toxins inhibit hepatic uptake of eprosartan. Clin Pharmacol Ther 2005; 77: 2.

22. Sun $\mathrm{H}$ et al. Hepatic clearance, but not gut availability, of erythromycin is altered in patients with end-stage renal disease. Clin Pharmacol Ther 2010; 87: 465-472.

23. Nolin TD et al. ESRD impairs nonrenal clearance of fexofenadine but not midazolam. J Am Soc Nephrol 2009; 20: 2269-2276.

24. Yamaguchi $\mathrm{H}$ et al. Rapid screening of antineoplastic candidates for the human organic anion transporter OATP1B3 substrates using fluorescent probes. Cancer Lett, 2008; 260: 163-169.

25. Ishiguro $\mathrm{N}$ et al. Predominant contribution of OATP1B3 to the hepatic uptake of telmisartan, an 
angiotensin II receptor antagonist, in humans. Drug Metab Dispos 2006; 34: 1109-1115.

26. Fujita $K$ et al. Direct inhibition and down-regulation by uremic plasma components of hepatic uptake transporter for SN-38, an active metabolite of irinotecan, in humans. Pharm Res 2014; 31: 204-215.

27. Vavricka SR et al. Interactions of rifamycin SV and rifampicin with organic anion uptake systems of human liver. Hepatology 2002; 36: 164-172.

28. Vanholder $\mathrm{R}$ et al. Review on uremic toxins: classification, concentration, and interindividual variability. Kindney Int 2003; 63: 1934-1943.

29. Meijers BK et al. A review of albumin binding in CKD. Am. J Kidney Dis 2008; 51: 839-850.

30. Małgorzewicz $S$ et al. Serum concentration of amino acids versus nutritional status in hemodialysis patients. J Ren Nutr 2008; 18: 239-247.

31. Leblond $F$ et al. Downregulation of hepatic cytochrome P450 in chronic renal failure. J Am Soc Nephrol 2001; 12: 326-332.

32. Naud $J$ et al. Effects of chronic renal failure on liver drug transporters. Drug Metab Dispos 2008; 36: 124-128.
33. Naud $\mathrm{J}$ et al. Current understanding of drug disposition in kidney disease. J Clin Pharmacol 2012; 52: 10S-22S.

34. Weiss $\mathbf{J}$ et al. Influence of sildenafil and tadalafil on the enzyme- and transporter-inducing effects of bosentan and ambrisentan in LS180 cells. Biochem Pharmacol 2013; 85: 265-273.

35. Pawlak D et al. Accumulation of toxic products degradation of kynurenine in hemodialyzed patients. Int Urol Nephrol 2001; 33: 399-404.

36. Toyohara $\mathrm{T}$ et al. Metabolomic profiling of uremic solutes in CKD patients. Hypertens Res 2010; 33: 944-52.

37. Volpe DA. et al. Effect of uremic serum and uremic toxins on drug metabolism in human microsomes. Regul Toxicol Pharmacol 2014; 68: 297-303.

38. Barnes KJ. et al. Inhibition of human drug-metabolising cytochrome P450 and UDP-glucuronosyltrans -ferase enzyme activities in vitro by uremic toxins. Eur J Clin Pharmacol 2014; 70: 1097-1106. 